\title{
Por uma teoria lingüística que fundamente o ensino de língua materna \\ (ou de como apenas um pouquinho de gramática nem sempre é bom)
}

\author{
Carlos Alberto Faraco \\ Gilberto de Castro
}

\begin{abstract}
RESUMO
As críticas que a lingüística fez até hoje ao ensino tradicional de língua materna levantaram questões importantes sobre os temas da gramática, da leitura e da redação. No entanto, parece-nos que o esforço de resolução dessas questões sempre teve um caráter mais prático do que teórico. Nesse sentido, o que se aborda aqui é uma tentativa de refletir sobre os problemas do ensino de português, partindo de uma reflexão teórica mais abrangente sobre linguagem, reflexão esta inspirada no teórico russo Mikhail Bakhtin.

Palavras chaves: Bakhtin, lingüística, língua materna, ensino.
\end{abstract}

\begin{abstract}
Linguistic criticism on traditional native language teaching has raised important questions about the teaching of grammar, reading and writing. Nonetheless, answers to these questions have been more practical than theoretical. This paper aims at thinking over problems in Portuguese teaching, from a broader theoretical viewpoint on language, which is based upon theories, proposed by the Russian Mikhail Bakhtin.

Key-words: Bakhtin, linguistics, native language, teaching.
\end{abstract}

\section{Introdução}

O ensino de língua materna, desde as primeiras letras até o estudo da nossa tradição literária, tem sido alvo de preocupação de especialistas das mais variadas áreas. Assim, o ensino de linguagem, de um modo geral, vem sendo há algum tempo tema de discussão de gramáticos, pedagogos, psicólogos etc. que, evidentemente, centraram seus estudos e críticas segundo pressupostos e pontos de vista próprios às suas áreas de conhecimento. Mais recentemente (de 25 anos para cá, mais ou menos), os lingüistas se integraram ao debate, contribuindo de forma original na crítica ao modo como a escola trata o ensino de linguagem. Ao apontar as fragilidades encontradas no ensino tradicional ao lidar com as diferenças culturais e lingüísticas dos novos alunos que se integraram à escola pública brasileira, por conta de sua expansão nos governos militares, os lingüistas deram um novo tom à discussão, redirecionando o debate a partir, principalmente, da inserção do tema da variação lingüística e suas decorrências, seja quanto ao conceito de gramática, seja quanto à funcionalidade das variantes.

Esse viés novo dos lingüistas foi a base da geração de toda uma nova bibliografia que, na última década, particularmente, invadiu as livrarias do país, enfocando de forma qualitativamente diferenciada, se comparada à produção bibliográfica anterior, temas como alfabetização, ensino de gramática, ensino de redação, de leitura etc.

Mas qual é, afinal, o núcleo da crítica que os lingüistas fizeram em relação ao ensino de língua materna?

A crítica básica e fundamental dos lingüistas ao ensino tradicional recaiu sobre o caráter excessivamente normativo do trabalho com a linguagem nas escolas brasileiras. Segundo essa crítica, as nossas escolas, além de desconsiderarem a realidade multifacetada da língua, colocaram de forma desproporcional a transmissão das regras e conceitos presentes nas gramáticas tradicionais como o objeto nuclear de estudo, confundindo, em conseqüência, ensino de língua com o ensino de gramática. Aspectos 
relevantes do ensino da língua materna, como a leitura e a produção de textos, acabaram sendo deixados de lado.

Mas, se o ensino de linguagem não se dá, como querem os tradicionalistas, calcado no eixo normativo, como ele deve ser, se aceitarmos a crítica dos lingüistas? Em outras palavras, quando tiramos de foco o ensino de regras e conceitos, o que passa a ser o nosso objeto de ensino?

A resposta central dos lingüistas a essa pergunta é que o objeto de estudo privilegiado no ensino de linguagem, ao abandonarmos o formalismo gramatical, deve ser o texto, na medida em que ele é, de fato, a manifestação viva da linguagem. Nesse sentido, até mesmo o ensino dos aspectos normativos estaria subordinado ao trabalho com o texto, isto é, as regras gramaticais não seriam mais ensinadas por meio de frases soltas, abstraídas de contexto, e sim na perspectiva de sua funcionalidade textual. Em outras palavras, a proposta dos lingüistas reivindica o abandono da memorização exaustiva dos conceitos e normas gramaticais em frases descontextualizadas, em favor da percepção prático-intuitiva dos fatos gramaticais presentes no texto. Em síntese, parece claro que essa mudança de visão sobre o ensino de linguagem, embora à primeira vista possa parecer apenas uma mudança de opção prática, aponta para problemas de ordem teórica a cerca da linguagem que transcendem os limites da preocupação exclusiva com o seu ensino.

Quando os lingüistas criticam a prática maniqueísta e prescritiva da escola, estão de fato rejeitando os seus fundamentos, ou seja, a concepção de linguagem dos gramáticos. A crítica à prática esconde, assim, uma rusga epistemológica surda, mas muito real. Isso fica especialmente claro na solução prática que os lingüistas encontraram para opor ao ensino tradicional. Ao elegerem o texto como objeto central do ensino, eles estão implicitamente sugerindo um outro entendimento do que vem a ser a linguagem. Agora, ao invés de um olhar monológico sobre a relação do ser humano com a linguagem, temos uma proposta que assume, mesmo que implicitamente, que o aprendizado com a linguagem se dá por meio do uso que fazemos dela na interação (oral ou escrita) que estabelecemos com o outro, seja ele real ou virtual.

Embora possamos considerar positiva a proposta dos lingüistas, ela não deixa de ter seus problemas. É o que se percebe quando analisamos a proposta de encaminhamento do estudo gramatical que, como vimos, sugere um trabalho que se distancia do formal, incentivando a intuição do aluno com a linguagem. Contudo, entende-se muitas vezes, nesse contexto, que basta exercitar a intuição e abandona-se totalmente o ensino de gramática, o que, segundo o nosso ponto de vista, é um equívoco.

Se é verdade que alguns tópicos de gramática (principalmente aqueles mais relacionados aos cuidados básicos que se deve ter na produção de um texto escrito, tais como, concordância verbal e nominal, colocação pronominal, por exemplo) são passíveis de um ensino apenas prático-intuitivo, também é verdade que esse modo de abordar a gramática não é suficiente quando nos propomos a pensá-la não como um aglomerado dogmático e solidificado de regras e exceções, mas como o principal documento de consulta sobre um número grande de fatos da língua mais formal, oral e escrita.

Em outras palavras, parece-nos que a proposta dos lingüistas com relação ao ensino gramatical, mesmo de forma não intencional, sugere a exclusão da gramática da escola. E é difícil concordar com isso, porque apesar de todas as críticas que possamos fazer à gramática em virtude de suas imperfeições e impropriedades conceituais e empíricas, temos de admitir que ela ainda é a principal fonte de referência da normatização da linguagem-padrão falada e escrita do país. Além disso, a tradição gramatical nos fornece uma metalinguagem bastante útil para tratar das línguas humanas, metalinguagem que a própria lingüística contemporânea pouco alterou.

Além desse distanciamento da tradição gramatical, embutido na proposta mais prática de encaminhamento do ensino de linguagem, elaborada pelos lingüistas, há ainda um outro problema. No trabalho com professores, e com acadêmicos do curso de Letras da Universidade Federal do Paraná, uma coisa que costumamos ouvir sempre é que a proposta de se trabalhar com o texto é boa, mas, como não há forma de fugir do normativo, uma vez que o uso da linguagem deve respeitar determinadas regras, dar um pouquinho de gramática sempre é bom.

Aparentemente essa expressão parece combinar com a idéia de ensinar a gramática no texto, isto é, com a forma prático-intuitiva de se estudar as regras gramaticais a que já nos referimos. Contudo, não é assim que muitos professores e alunos percebem o problema ao fazerem uso da expressão destacada acima. Para eles, dar um pouquinho de gramática materializa a necessidade de não abandonar o trabalho formal e abstrato com a gramática tradicional, integrando-o ao trabalho com o texto. Indiretamente, com essa expressão, o que eles nos dizem parece funcionar como uma cobrança de que em algum lugar a coisa não está assim tão clara. No entanto, a integração que realizam acaba por aglutinar pressupostos de entendimento e trabalho com a linguagem completamente antagônicos. Ou seja, o que fazem é a junção eclética de concepções de linguagem distintas: quando se privilegia o trabalho com o texto, olham a linguagem pela via da interação; quando 
partem para o estudo gramatical, revelam-se seguidores autênticos da concepção gramatical tradicional, tratando dos conceitos e estruturas gramaticais de forma monolitica e cristalizada, tal qual o faria um velho gramático.

Alguém pode dizer que essa situação só acontece porque a formação de nossos professores é muito ruim e, por isso, eles têm dificuldade de entender e empreender mudanças qualitativas no ensino de língua materna. Com tal afirmação nós certamente concordaríamos, mas não sem acrescentar que numa situação em que tivéssemos um professor mais bem formado o problema persistiria. E persistiria pela razão que já enumeramos, isto é, porque o encaminhamento essencialmente prático das discussões dos lingüistas sobre o ensino de linguagem é incapaz de esclarecer uma questão como essa. Em outras palavras, a questão de como incluir o trabalho formal com a gramática tradicional em nossas salas de aula, sem transformar o nosso ensino num ensino puramente normativo, só pode ser resolvida a partir de uma reflexão teórica sobre a linguagem capaz de abarcar a realidade lingüística multifacetada presente na sala de aula.

O ponto relativo ao ensino da gramática com certeza é o que mais polêmica tem gerado no âmbito das discussões sobre o ensino de linguagem de um modo geral. Mas há outros, igualmente importantes, para os quais o viés prático de discussão dos lingüistas deixa a desejar. O mais importante deles talvez seja a falta de uma conceituação mais segura do que venha ser o texto de que tanto falamos.

Em relação a esse conceito em particular, temos a impressão de que a lingüística mais tradicional tem pouco a dizer. E quando vamos para a hoje chamada lingüística do texto o que percebemos é mais uma análise das relações internas referentes a ele (reparemos, por exemplo, na excessiva bibliografia hoje existente sobre as discussões de coesão e coerência) do que uma preocupação conceitual que busque uma generalização sobre a noção de texto, que consiga transcender os elementos meramente formais e de ligação interna.

Temos, ainda, no âmbito da lingüística, a chamada análise do discurso que, como o próprio nome indica, se preocuparia com as questões relativas à linguagem nas suas formas de utilização. Contudo, essa análise, na maioria das suas manifestações, ainda está bastante atada a um modo de interpretar os fenômenos lingüísticos de forma desvinculada do contexto mais amplo da vida. A análise do discurso é hoje, na lingüística, uma teoria híbrida sobre a linguagem: de um lado, ela estica o olhar para ver se descobre os mistérios da linguagem viva; e, de outro, não consegue de fato exorcizar o modo estruturalista de ver a linguagem sob o prisma das relações formais.

Essa limitação da lingüística, de um modo geral, em conceituar o texto nos incentiva ainda mais a uma busca de solução teórica que possa dar conta não só desse problema ou do problema relativo à gramática, mas que também seja, por força de uma heurística mais abrangente, capaz de antever e resolver novos tipos de problemas.

Essa busca teórica, no entanto, não deve ser entendida aqui como a negação da prática, já que, como salientamos anteriormente, toda teoria, se se quer creditada, tem de ser testada praticamente. O problema é que estamos muito acostumados, no sentido negativo do termo, a ver a prática de ensino de linguagem como algo que prescinde de teoria ou de preocupações epistemológicas mais profundas uma vez que, infelizmente, até para muitos lingüistas, o ato de ensinar é muito mais resultado de inspiração e palpite do que um esforço no sentido de também iluminar aspectos relativos à linguagem. Acreditamos, ao contrário, que a teoria desempenha um importante papel na nossa atividade. Ela é um impulso vigoroso para a nossa prática porque estimula a nossa intuição na busca da autonomia, originalidade e independência de trabalho. É claro que esse dinamismo de trabalho, com relação especificamente à prática de ensino de linguagem, pode ser conseguido pelo contínuo exercício da prática, mas sempre à custa de um gasto de tempo bem maior e, em muitos casos, através da utilização dispendiosa de recursos humanos e financeiros. Além do mais, a preocupação com a teorização é um excelente antídoto contra a repetição e a banalidade de nossas práticas.

Nesse ponto da discussão, é importante deixar claro que o fato de estarmos defendendo a necessidade de nos preocuparmos com a relação teoria $x$ ensino, em nenhum momento deve ser interpretado como uma defesa de que existe uma teoria ou um teórico cujo trabalho científico foi elaborado com a única e exclusiva função de ser aplicado a problemas relativos ao ensino de linguagem; ou que dê a infame "palavra final" sobre o assunto. O que pode, sim, ocorrer, é nos utilizarmos do potencial explicativo de determinada teoria lingüística para a interpretação e possível resolução dos problemas que afetam a nossa área de atuação.

Nesse sentido, cabe-nos, então, perguntar: a que teórico, dentre os muitos conhecidos, recorreríamos hoje para nos auxiliar na nossa empreitada de professores da língua materna? Que teoria atualmente inclui no seu quadro geral possibilidade heurística de, a partir dela, pensarmos o ato de se ensinar linguagem?

Um teórico que tem sido mencionado constantemente na última década e relacionado, juntamente com VIGOTSKY, aos problemas relativos ao processo de ensino-aprendizagem, é Mikhail BAKHTIN. Esse teórico russo foi publicado pela primeira vez no Brasil no final da década de 70, quando começava o processo de 
abertura política no país. O seu primeiro livro publicado aqui foi Marxismo e filosofia da linguagem, em 1979. Nesse trabalho, o autor, ao criticar as duas principais teorias lingüísticas em curso no seu tempo, construiu a base de sua epistemologia lingüística. A esse texto, seguiu-se toda uma série de outros, cuja temática se divide basicamente entre as preocupações com a linguagem, estética geral e estética literária.

Apesar desse relativamente curto espaço de tempo de circulação entre nós, o pensamento de BAKHTIN tem exercido grande atração sobre os educadores e se transformou numa referência constante nos últimos anos. De um lado, talvez, pelo excessivo apelo que o novo sempre exerce sobre nós, fazendo-nos muitas vezes seguir acriticamente os ventos da moda; mas, de outro, com certeza, em virtude da grande mudança de enfoque que BAKHTIN realiza ao olhar a relação entre o ser humano, a sociedade e a linguagem.

Contudo, apesar de estar na ordem do dia das referências e citações sobre o ensino de um modo geral, sobre o ensino de linguagem especificamente e também sobre questões relativas à literatura, as idéias de BAKHTIN na maioria das vezes parecem, ainda hoje, inspirar apenas algumas palavras de ordem - tais como: ser humano e linguagem são inseparáveis; ou a natureza da linguagem é sociológica, por exemplo -, normalmente identificadas com o ponto de vista geral do autor sobre linguagem. Essas palavras de ordem são, evidentemente, insuficientes para o enfrentamento dos problemas concretos da realidade lingüísticopedagógica. Em outras palavras, a tradicional e necessária ponte entre a teoria e a prática ainda está por se fazer no que se refere à relação das idéias lingüísticas de BAKHTIN com o ensino de linguagem.

No sentido de dar uma contribuição com relação ao tema, vamos tentar analisar aqui alguns problemas relativos ao ensino de língua materna à luz da teoria de BAKHTIN. Ou seja, nossa intenção é mostrar onde e por que encontramos, na teoria desse autor, respaldo para uma melhor interpretação da situação da sala de aula de língua portuguesa.

Como já dissemos anteriormente, a substituição do enfoque gramatical pelo enfoque interativo-textual, proposto pelos lingüistas, só na aparência pode ser entendida como uma mudança puramente prática. Antes de mais nada, o que essa mudança revela é que o desejo de transformar o ensino de língua materna em algo real, o desejo de restaurar no espaço da sala de aula o processo de interlocução viva, só é possível a partir de uma nova percepção da realidade da linguagem viva. Alcir PÉCORA (1983), em seu competente Problemas de redação, já alertava para isso ao analisar o fracasso apresentado pelos estudantes em relação a tópicos básicos da norma-padrão. Na avaliação do autor:

[...] é preciso reconhecer que esse [o não-domínio da norma-padrão] não é um problema de origem pedagógica, não adianta introduzir mil técnicas-revolucionárias-de-motivação: trata-se de um fracasso alimentado a fermento pela concepção de língua que condiciona todo o ensino oficial do português e que, ao desconhecer a complexidade vital de seus usos, torna-se incapaz de garantir o aprendizado adequado de um só deles. (PÉCORA, 1983, p. 37-38)

Quando o texto vem substituir o centralismo gramatical, como vimos, o que acontece é uma alteração de pressupostos teóricos, uma mudança, portanto, de concepção de língua, como bem enfatiza PÉCORA. O problema que permanece é que no quadro da lingüística - entendida aqui como toda corrente de pensamento e de prática em lingüística, antiga ou contemporânea, em cuja composição científica a preocupação formal ainda tenha primazia - o seu apelo não podia encontrar eco, uma vez que a interação e a linguagem viva nunca foram objeto de preocupação desse modo de pensar a linguagem.

Contemporaneamente, vamos encontrar em BAKHTIN formas de justificar por que devemos mudar de concepção de linguagem se queremos entender, em toda a sua complexidade, o ato de ensinar a nossa língua nas escolas. Isso porque o recorte de estudo da linguagem que empreende BAKHTIN é inteiramente voltado para o fenômeno da interlocução viva. Todo o esforço do autor, particularmente nos capítulos 5 e 6 de Marxismo..., a polemizar com as teses principais de HUMBOLDT e SAUSSURE, é o de delimitar o real objeto de estudo da lingüística, complementando a reflexão que realiza nos primeiros capítulos do livro quando discute a origem social dos signos e dos enunciados humanos. Para ele: "A língua vive e evolui historicamente na comunicação verbal concreta..." (BAKHTIN, 1986, p. 124), logo:

A verdadeira substância da língua não é constituída por um sistema abstrato de formas lingüísticas, nem pela enunciação monológica isolada, nem pelo ato psicofisiológico de sua produção, mas pelo fenômeno social da interação verbal, realizada através da enunciação ou das enunciações. A interação verbal constitui assim a realidade fundamental da língua. (BAKHTIN, 1986, p. 123) 
Se é a interação verbal o que importa, temos então aí a primeira grande reivindicação colocada pela teoria em relação a nossa atitude como professor de linguagem, que é a de privilegiar não só o contato freqüente de nosso aluno com a leitura e a produção de textos, como também fazer dessa leitura e dessa produção uma relação lingüística viva. Como diz PÉCORA, na conclusão do livro, citado anteriormente, ao referir-se à prática da escrita, "[...] o efetivo domínio da prática escrita apenas pode se dar como um desdobramento da práxis lingüística e jamais como uma mera assimilação de técnicas e padrões." Até onde os limites naturalmente laboratoriais da escola permitirem, isso eqüivale a dizer que o nosso aluno precisa ser estimulado a tomar consciência de que o ato de falar e escrever - no caso da escola, principalmente escrever é um processo de estabelecimento de interação social com um outro, seja esse outro um colega próximo da sala, a redação de uma revista de circulação local ou nacional, ou interlocutor imaginário.

A concepção de linguagem de BAKHTIN, em seus princípios mais gerais, pode, portanto, fundamentar uma proposta lingüístico-pedagógica interacional, dando o suporte inicial e necessário para uma mudança qualitativa em nossa tradição de ensino da língua. Além disso, autentica a crítica dos lingüistas com relação aos estudos exclusivamente gramaticais, quando, ao refazer o percurso histórico que marcou o pensamento abstrato/formal nos estudos da linguagem, aquele autor mostra que as gramáticas são construções decorrentes da reflexão humana, que funcionaram como descrição da língua e como suporte pedagógico. Em suas palavras:

[...] criar o instrumental indispensável para a aquisição da língua decifrada, codificar essa língua no propósito de adaptá-la às necessidades da transmissão escolar, marcou profundamente o pensamento lingüístico. A fonética, a gramática, o léxico, essas três divisões do sistema da língua, os três centros organizadores das categorias lingüística, formaram-se em função das duas tarefas atribuídas à lingüística: uma heurística e a outra pedagógica. (BAKHTIN, 1986, p. 99)

É esse viés de ensino de linguagem que os nossos lingüistas contemporâneos criticaram, mas sem a contrapartida epistemológica necessária. Em outros termos, para rejeitar a pouca eficácia do ensino descritivo/reflexivo tradicional não é suficiente propor apenas uma solução prática - como a substituição do caráter reflexivo formal pela relação interacional com o texto -; é preciso, também, como já frisamos antes, justificar teoricamente essa nossa atitude como forma de concretizar uma metodologia extensivamente conseqüente.

Quando BAKHTIN, ao discutir o pensamento de SAUSSURE, reflete sobre como é a nossa relação efetiva com a linguagem, ele, indiretamente, nos indica como se dá o aprendizado lingüístico e justifica, por conseqüência, por que devemos abandonar a tradição formalista/estruturalista no ensino de linguagem. Ao referir-se ao locutor (falante ou escritor), o autor vai dizer que este "serve-se da língua para suas necessidades enunciativas concretas. [...] Trata-se, para ele, de utilizar as formas normativas [...] num dado contexto concreto." (BAKHTIN, 1986, p. 92)

E continua afirmando, ainda para o locutor, que:

[...] o que importa é aquilo que permite que a forma lingüística figure num dado contexto, aquilo que a torna um signo adequado às condições de uma situação concreta dada. Para o locutor, a forma lingüística não tem importância enquanto sinal estável e sempre igual a si mesmo, mas somente enquanto signo sempre variável e flexível. Este é o ponto de vista do locutor. (BAKHTIN, 1986, p. 92-93).

Com relação ao receptor (ouvinte ou leitor), segundo BAKHTIN, as coisas vão funcionar também da mesma maneira, uma vez que o centro organizador da linguagem não está no sistema lingüístico e sim no contexto de interação verbal. Assim:

[...] o essencial na tarefa de descodificação não consiste em reconhecer a forma utilizada, mas compreendê-la num contexto concreto preciso, compreender sua significação numa enunciação particular. Em suma, trata-se de perceber seu caráter de novidade e não somente sua conformidade à norma. Em outros termos, o receptor, pertencente à mesma comunidade lingüística, também considera a forma lingüística utilizada como um signo variável e flexível e não como um sinal imutável e sempre idêntico a si mesmo (BAKHTIN, 1986, p. 93) 
Outro ponto, sobre o qual encontramos amparo na reflexão de BAKHTIN, diz respeito ao modo como devemos nos relacionar com as formalizações. À primeira vista, pode parecer que a perspectiva sociológica de BAKHTIN recusa qualquer tipo de trabalho formal com a linguagem (os que não lêem BAKHTIN normalmente tiram conclusões desse tipo); contudo, essa impressão logo se desfaz quando prestamos melhor atenção ao que o autor diz a respeito do abstracionismo radical da maioria dos estruturalistas - crítica, aliás, completamente válida também para gramáticos e formalistas de um modo geral.

Para ele, "Todo procedimento abstrato, para se legitimar, deve ser justificado por um propósito teórico e prático preciso. Uma abstração pode ser fecunda ou estéril, útil para certos fins e determinadas tarefas e não para outras." (BAKHTIN, 1986, p. 96); mas o propósito para o qual SAUSSURE e seguidores elaboraram o sistema acabou por perder-se em exageros, já que os estruturalistas pretendiam que o seu modelo abstrato da língua eqüivalesse à natureza mesma da língua. É precisamente sobre esse ponto que recai a discordância de BAKHTIN em relação à perspectiva de SAUSSURE. Contudo, isso não significa dizer que o autor não reconheça os méritos e as conquistas pertencentes aos estruturalistas no estudo da linguagem. Em outras palavras, não há nada de condenável no ato de formalizar, desde que essa nossa atitude, no caso específico da teoria de BAKHTIN, esteja voltada para a interação verbal ou, falando especificamente de ensino, desde que o nosso trabalho como professor, com estruturas e frases eventualmente descontextualizadas, tenha por finalidade última não a memorização de conceitos, mas o uso efetivo da linguagem.

O trabalho com frases e estruturas isoladas, no entanto, exige cuidado, caso contrário podemos incorrer num normativismo disfarçado a que nos referimos ao mencionar a precariedade da proposta dos lingüistas para tratar de questões normativas fora das relações textuais. Nesse sentido, mais uma vez o ponto de vista histórico-sociológico de BAKHTIN sobre a linguagem também nos auxilia.

A lingüística critica, por exemplo, os conceitos presentes nas gramáticas tradicionais por serem esses imprecisos e, por isso, insuficientes para darem conta dos fatos normativos da língua. Entretanto, seguindo a polêmica que BAKHTIN empreende com os formalistas e estruturalistas ao longo dos seus textos, podemos perceber a incrível semelhança de olhar para a linguagem existente entre os gramáticos e grande parte de nossos lingüistas: tanto uns como outros, crêem na possibilidade de entendimento dos fenômenos relativos à linguagem apenas a partir da descrição formal dos seus fatos, ou seja, via o estudo e a criação de gramáticas. Disso decorre que não está ao alcance da maioria dos lingüistas entender como integrar o estudo normativo abstrato a uma perspectiva interacionista de ensino de linguagem.

O que estamos querendo dizer é que é preciso, sim, reinstaurar o trabalho formal com a gramática tradicional dentro de nossas salas de aula, mas de uma maneira funcional, isto é, fazendo com que o nosso aluno passe a conhecê-la, não só como um aglomerado de inadequações explicativas sobre os fatos da língua, mas - embora arcaica em boa parte de suas observações empíricas - como um documento de consulta para muitas das dúvidas que temos sobre como agir em relação aos padrões normativos exigidos pela escrita. A teoria de BAKHTIN nos dá sustentação teórica para um trabalho como esse porque, em primeiro lugar, vê a linguagem dialética e historicamente e não tem, por conseqüência disso, nenhuma dificuldade em reinterpretar de forma produtiva o trabalho realizado pelos gramáticos, muito menos em avaliar que uma gramática é, e sempre será, uma descrição parcial e circunstancial de alguns fatos da língua. E, em segundo lugar, porque ao colocar a interação como o centro de preocupação de nossos estudos sobre a linguagem, o autor está nos indicando a necessidade de a reflexão formal - no caso específico de nossa discussão, a reflexão normativa tornar-se função da interlocução, do uso da linguagem efetivamente. Seguindo essa idéia, é possível, portanto, reinstaurar o trabalho com a gramática tradicional dentro da sala de aula, tornando-a instrumento auxiliar na busca do domínio da norma padrão por parte do nosso aluno. Entretanto, não há como fazer isso sem que o aluno passe a conhecer a finalidade da gramática tradicional, a sua estrutura, a sua terminologia e os seus conceitos principais, sem os quais não há como acessar as suas informações e torná-la um livro de consultas; esse trabalho, por sua vez, só pode se realizar através da reflexão formal sobre o conteúdo de nossas gramáticas.

Outro ponto em que a teoria de BAKHTIN nos ajuda se relaciona ao conceito de texto. Quando os lingüistas, ao discutirem problemas relativos ao ensino de língua portuguesa, falam da interlocução na produção de textos, implicitamente deixam entender que operam com a idéia de que texto é linguagem colocada em uso, uma vez que a sua construção visa o estabelecimento da comunicação entre os interlocutores. Apesar de ficar subentendido, como já afirmamos anteriormente, esse conceito ainda assim carece de precisão. Essa precisão, no entanto, parece não estar ao alcance de uma lingüística mais tradicional pelas mesmas razões que apresentamos acima para os problemas relativos ao ensino gramatical, ou seja: o viés teórico que dá o tom a nossa lingüística atual é, ainda, por vezes excessivamente formalista e, por essa 
razão, tem problemas para enxergar o texto fora de seus limites internos. Não por acaso é comum entre os lingüistas falar-se, nesse caso, numa "gramática do texto".

Embora o termo utilizado por BAKHTIN não seja texto, a sua reflexão sobre enunciado, desenvolvida basicamente em Marxismo..., e em Gêneros do Discurso e Problemas do Texto (ambos inacabados), parece servir como caracterização desse conceito, uma vez que para o autor o enunciado é linguagem em uso, não devendo ser confundido com nenhuma espécie de recorte em que se dê primazia ao material verbal. Nesse sentido, aliás, a fala de BAKHTIN relativa à confusão entre oração e enunciado que os lingüistas do seu tempo faziam, parece-nos bastante atual. Para ele:

\begin{abstract}
Muitos lingüistas (no campo da sintaxe) são prisioneiros dessa confusão: o que estudam é, na realidade, uma espécie de híbrido da oração (unidade da língua) e do enunciado (unidade da comunicação verbal). As pessoas não trocam orações, assim como não trocam palavra (numa acepção rigorosamente lingüística), ou combinações de palavras, trocam enunciados constituídos com a ajuda das unidades da língua - palavras, conjunto de palavras, orações; mesmo assim, nada impede que o enunciado seja constituído de uma oração, ou de uma única palavra, por assim dizer, de uma unidade da fala (o que acontece sobretudo na réplica do diálogo), mas não é isso que converterá uma unidade da língua numa unidade da comunicação verbal (BAKHTIN, 1992, p. 297).
\end{abstract}

Para o autor, a relação lingüística entre os seres humanos se dá, portanto, por meio do enunciado (oral ou escrito), que é o processo básico de estabelecimento da interlocução e envolve, por isso, obrigatoriamente, um contexto específico e interlocutores correspondentes a esse contexto, com seus valores e interesses. $\mathrm{O}$ enunciado em BAKHTIN se caracteriza, assim, por ser uma ação lingüística viva que se constrói no complexo jogo das relações humanas. Em outras palavras, a elaboração do enunciado, que vai da intenção semânticoideológica a sua materialização formal num léxico, numa sintaxe e numa estrutura específica é função da interação (da interlocução). É por isso que BAKHTIN vai dizer que: "na realidade não são palavras o que pronunciamos ou escutamos, mas verdades ou mentiras, coisas boas ou más, importantes, triviais, agradáveis ou desagradáveis, etc. A palavra está sempre carregada de um conteúdo ou de um sentido ideológico ou vivencial"' (BAKHTIN, 1986, p. 95).

Do ponto de vista metodológico, o conceito de enunciado de BAKHTIN - daqui para frente, também de texto - é um princípio teórico importante, porque pode elucidar algumas de nossas ações que dizem respeito ao modo como conduzimos o trabalho de leitura e de prática de texto na sala de aula.

Com relação à leitura, o princípio nos indica que a produtividade do ato de compreensão da palavra alheia, do texto que o nosso aluno lê, está diretamente ligada à capacidade do professor de reconstruir os determinantes contextuais - contexto histórico imediato ou distante, situação do autor nesse contexto (seus valores), influências estilísticas e/ou ideológicas do autor ou dos autores etc. - geradores do texto, cobrindo-o com questões pertinentes que busquem explorar aqueles aspectos que uma leitura superficial normalmente deixa escapar.

Em suma, uma boa leitura tem de ser capaz de preencher os claros e os implícitos indicados pelo texto, reconstruindo dessa forma o referencial amplo do dizer do autor. Esse é o primeiro passo na direção de uma possibilidade valorativa do aluno em relação ao texto do autor. A nosso ver, esse deve ser um dos grandes objetivos do trabalho de leitura, uma vez que o exercício de confronto com a palavra do outro é um fator preponderante na formação da subjetividade discursiva do nosso aluno.

Mas o conceito de enunciado de BAKHTIN não é produtivo somente em relação ao trabalho com a leitura. Ele também é útil para refletirmos sobre a produção textual que desenvolvemos na escola. Para esse autor, os enunciados que criamos nos mais variados contextos sociais possuem aspectos discursivos (semânticos e formais) relativamente estáveis que vieram se desenvolvendo ao longo do tempo, a ponto de BAKHTIN denominá-los de gêneros do discurso. Nas suas palavras:

A riqueza e a variedade dos gêneros do discurso são infinitas, pois a variedade virtual da atividade humana é inesgotável, e cada esfera dessa atividade comporta um repertório de gêneros do discurso que vai diferenciando-se e ampliando-se à medida que a própria esfera se desenvolve e fica mais complexa. Cumpre salientar de um modo especial a heterogeneidade dos gêneros do discurso (orais e escritos), que incluem indiferentemente: a curta réplica do diálogo cotidiano (com a diversidade que este pode apresentar conforme os temas, as situações e a composição de seus protagonistas), o relato familiar, a carta (com suas variadas formas), a ordem militar padronizada, em sua forma lacônica e em forma de ordem circunstanciada, o repertório bastante diversificado dos documentos oficiais (em sua maioria padronizados), o universo das declarações públicas (num sentido amplo, as sociais, as políticas). E é 
também com os gêneros do discurso que relacionaremos as variadas formas de exposição científica e todos os modos literários (desde o ditado até o romance volumoso). (BAKHTIN, 1992, p. 279-280).

O fato de que os enunciados possuem uma padronização motivada historicamente assume importância capital para entendermos a nossa relação com a linguagem. Segundo BAKHTIN, esses enunciados assumem para nós extrema relevância no aprendizado de nossa língua, porque:

\begin{abstract}
A língua materna - a composição de seu léxico e sua estrutura gramatical -, não a aprendemos nos dicionários e nas gramáticas, nós a adquirimos mediante enunciados concretos que ouvimos e reproduzimos durante a comunicação verbal viva que se efetua com os indivíduos que nos rodeiam. Assimilamos as formas da língua somente nas formas assumidas pelo enunciado e juntamente com essas formas. As formas da língua e as formas típicas de enunciados, isto é, os gêneros do discurso, introduzemse em nossa experiência e em nossa consciência juntamente e sem que sua estreita correlação seja rompida. Aprender a falar é aprender a estruturar enunciados (porque falamos por enunciados e não por orações isoladas e, menos ainda, é óbvio, por palavras isoladas). Os gêneros do discurso organizam nossa fala da mesma maneira que a organizam as formas gramaticais (sintáticas) (BAKHTIN, 1992, p. 301-302).
\end{abstract}

Disso tiramos que falar ou escrever é, antes de tudo, uma experiência lingüística com os diversos gêneros discursivos existentes no nosso tempo; são as formas relativamente estáveis desses gêneros que organizam a nossa expressão. Assim, quando falamos ou escrevemos, estamos na verdade atualizando formas relativamente consagradas de interação lingüística. Um resenhista de literatura, por exemplo, ao redigir o seu texto para a revista, não apenas atualiza a gramática da sua língua, nem cria o gênero da resenha no ato da escrita; o que ele realmente faz é se apropriar de um projeto de texto constituído historicamente, renovando-o com um novo tema (um novo livro, um autor desconhecido), um estilo pessoal (irônico, suave, retórico etc.), uma expectativa interlocutiva específica (características do interlocutor médio da revista) etc. Esse exemplo, respeitadas as características estilísticas próprias relativas a outros tipos de gêneros, de forma geral, aplica-se igualmente a todos eles. Resumindo, com as palavras do próprio BAKHTIN, "O querer-dizer do locutor se realiza acima de tudo na escolha de um gênero discursivo." (BAKHTIN, 1992, p. 301)

Dessas idéias todas de BAKTHIN, relacionadas ao enunciado, podemos tirar algumas lições importantes para levar para a prática de texto na sala de aula. A primeira delas está ligada à diversidade de gêneros discursivos existentes. Se dermos uma olhada rápida pelos materiais didáticos que estão, ainda hoje, sendo produzidos no país, veremos que a grande maioria deles é extremamente pobre em termos da variedade de textos que apresentam; pode-se afirmar com segurança que eles não estimulam o aprendizado dos diferentes gêneros discursivos - texto informativo (nas suas mais variadas formas), resenhas (sobre diferentes objetos e estilos), resumos, textos dissertativos, propaganda, manuais de instrução, entrevistas etc. - porque se concentram demasiadamente nos gêneros literários (poesias e crônicas, geralmente), que não deixam de ser igualmente importantes quando aparecem de maneira não exclusiva. Isso tudo limita a interação do aluno com as diferentes formas de comunicação, prejudicando o seu aprendizado. Assim, uma lição importante que a teoria de BAKHTIN nos ensina, no que se refere à produção textual, é que ela começa na oportunização do contato do aluno com a maior variedade de gêneros discursivos possíveis. Viabilizando a exposição a um número variado de textos, o segundo aspecto a ser levado em consideração é que não basta apenas ler tipos diferentes de textos para aprender a produzi-los; é preciso também estimular a sua produção, afinal a linguagem, num sentido amplo, aprende-se mesmo é na interação verbal.

Esse estímulo, portanto, deverá sempre caminhar no sentido oposto à tradicional aula da redação, pois deve levar nosso aluno à idéia de que o ato de escrever exige particularidades genéricas que precisam ser respeitadas - determinados aspectos estilísticos de uma resenha, por exemplo, não estão presentes numa dissertação ou num texto de propaganda e vice-versa. Em suma, o professor de língua materna deve estimular o aluno a refletir sobre as diferenças genéricas existentes entre os mais variados tipos de textos. Cabe a ele mostrar o papel desses gêneros no processo social de interação verbal, como forma de garantir a competência e a adequação discursiva do aluno para as mais variadas situações de interação socioverbal a que ele poderá ser exposto fora dos limites escolares. Isto é, no fundo, o que devemos fazer como professores de língua materna é, mais do que tudo, seguindo os princípios teóricos de BAKHTIN, levar para dentro da sala de aula até onde o limite natural da escola permite - a realidade dinâmica das relações lingüísticas que estão acontecendo fora dela.

Com essa articulação entre o conceito de enunciado (texto) e a prática de ensino de língua moderna, encerramos aqui este ensaio, esperando ter conseguido revelar uma aplicação possível da teoria de BAKHTIN, 
ao ensino de língua. Com certeza, além dos aspectos que abordamos, há no trabalho desse autor todo um conjunto de idéias e avaliações sobre a relação entre o ser humano e a linguagem que, além de iluminar os problemas relativos ao seu ensino, podem igualmente contribuir para uma nova interpretação dos problemas de aprendizagem de um modo geral. Embora BAKHTIN não seja um teórico da psicologia ou da teoria da aprendizagem - pelo menos não da forma como tradicionalmente entendemos que deva ser um teórico dedicado a uma área de pesquisa científica -, muitas das suas idéias relativas à formação da consciência humana, trazidas à tona principalmente nas suas discussões com FREUD e algumas correntes da psicologia da sua época, contém uma heurística própria sobre cognição que ainda carece de desenvolvimento. A exegese dessa parte do seu trabalho, contudo, é tarefa para outros especialistas.

\section{REFERÊNCIAS}

BAKHTIN, M. Marxismo e filosofia da linguagem: problemas fundamentais do método sociológico na ciência da linguagem. São Paulo: Hucitec, 1986.

Estética da Criação Verbal. São Paulo: Martins Fontes, 1992.

PÉCORA, A. Problemas de redação. São Paulo: Martins Fontes, 1983. 